\title{
Atopic Dermatitis and the Atopic March: What Is New?
}

\author{
Annalisa Patrizi, ${ }^{1}$ Alessandro Pileri, ${ }^{1}$ Federica Bellini, ${ }^{2}$ Beatrice Raone, ${ }^{1}$ \\ Iria Neri, ${ }^{1}$ and Giampaolo Ricci ${ }^{2}$ \\ ${ }^{1}$ Division of Dermatology, Department of Internal Medicine, Geriatrics and Nephrology, University of Bologna, Via Massarenti 1, \\ 40138 Bologna, Italy \\ ${ }^{2}$ Department of Pediatrics, University of Bologna, Via Massarenti 9, 40138 Bologna, Italy
}

Correspondence should be addressed to Annalisa Patrizi, annalisa.patrizi@unibo.it

Received 8 April 2011; Accepted 14 June 2011

Academic Editor: Fabienne Rancé

Copyright (C) 2011 Annalisa Patrizi et al. This is an open access article distributed under the Creative Commons Attribution License, which permits unrestricted use, distribution, and reproduction in any medium, provided the original work is properly cited.

Objective. In this paper the authors review the management of atopic dermatitis (AD) and the association between AD and allergic respiratory diseases. Data Sources. PubMed databases, researching articles in the last 15 years. Results. Studies about atopic march are cross-sectional population studies at different ages. They show that the most important predisposing factor for atopy is a decrease of the filaggrin's expression. Conclusions. The most modern theories seem to show that the most important factor which starts the atopic march is represented by an impaired epidermal barrier. It causes an increase in skin permeability to allergens that could induce sensitization even in the airways. The major predisposing factor is a primary inherited epithelial barrier defect resulting from filaggrin gene mutation, but other factors may play a role in this complex mechanism. Further studies are needed to focus on $\mathrm{AD}$ treatment and preventive strategies.

\section{Introduction}

Atopic dermatitis (AD) is the commonest chronic cutaneous disease of childhood in the first years of life [1]. AD is often the first manifestation of allergic diseases. Literature data $[2,3]$ show a progression from AD to asthma: the so-called atopic march. In this paper we will focus reader's attention about the relationship between $\mathrm{AD}$ and respiratory allergic diseases.

\section{History of AD}

$\mathrm{AD}$ has a long history. It was firstly described in 1892 by Besnier [4] who named it "prurigo diathésique". In order to highlight a possible association between the skin flare and genetic constitution, in 1927 Brocq suggested the term "constitutional eczema". Wise and Sulzberger in 1933 changed this name into "atopic dermatitis", finally adopted by Hanifin and Rajka in 1980 [5]. This is the current denomination adopted in the USA, while in Europe the most common definition is atopic eczema. In 2004 the World Allergy Organisation (WAO) Committee suggested to call "atopic eczema" any inflammatory condition determined by an IgE reaction, suggesting that the presence of eczema in atopic patients could be associated with or herald the development of some allergic diseases such as rhinitis and asthma [6].

\section{Genetic State of Art}

$\mathrm{AD}$ may be the first manifestation of allergic diseases and may be the first step of the so-called atopic march. A crucial role is played by filaggrin (filament-aggregating protein) that is involved in the epidermal barrier function. It is important for water permeability and for blocking the entry of microbes and allergens [7]. Filaggrin aggregates the keratin filaments and this process is essential for the formation of a normal stratum corneum and for the hydration of the skin. The filaggrin gene (FLG), located on chromosome 1q21 in the epidermal differentiation complex, encodes profilaggrin, a phosphorylated protein, precursor of filaggrin protein. Studies about FLG have underlined the link between early childhood eczema and the subsequent development of asthma. This is due to defective epidermal barrier function 
leading to increased allergen penetration and sensitization. Smith and coworkers in 2006 [8] demonstrated an association between ichthyosis vulgaris and a mutation in FLG, located on chromosome 1q21 (R501X and 2282del4).

In their study 15 families have been studied; AD was present in $44 \%$ of individuals heterozygous for this gene and in $76 \%$ of homozygous individuals; none of the family member without mutation had AD. Actually it is thought that the frequency of null FLG mutations (5 in total) is $9 \%$ in the European population [9].

Further studies confirmed both filaggrin polymorphisms as a major risk factor for $\mathrm{AD}$ [10-15]. The International Study of Asthma and Allergies in Childhood showed that in a group of German children the presence of filaggrin variants increased more than 3 times the risk of developing $\mathrm{AD}$ and more than 2 times the risk of developing rhinitis regardless of the presence of $\mathrm{AD}[16]$.

Of course, ascertaining the precise contribution of FLG mutations to the overall prevalence of these atopic diseases is confounded by temporal and disease severity factors in conjunction with putative environmental effects.

$\mathrm{AD}$ and asthma present common immunological features, including elevated IgE levels, TH2 cytokines, lesional and peripheral eosinophilia, and common environmental triggers.

The hypothesis that asthma is secondary to allergic sensitization, occurring after epidermal skin barrier disruption, has been confirmed by the fact that asthma is found only in the subset of filaggrin mutation carriers with $\mathrm{AD}$, however the precise mechanisms through which filaggrin mutations contribute to asthma and allergic rhinitis still remain unknown.

\section{Epidemiology}

Eczema is a very frequent skin disease. The prevalence of this condition ranges from $7 \%$ to $30 \%$ in children and from $2 \%$ to $10 \%$ in adults. In the last decades it has been increased with a percentage double or triple higher, in the developed countries [1].

In about $70-80 \%$ of patients, $\mathrm{AD}$ is associated with increased total IgE serum levels. Atopic diseases have different peaks of incidence at different ages during childhood. AD and food allergies have the highest incidence in the first 2 years of life. Sensitization to inhalant allergens is rare at that time of life. In later childhood, the prevalence of $\mathrm{AD}$, food allergies, and food allergen sensitization decreases and the prevalence of asthma, allergic rhinitis, and sensitization to inhalant allergens rises [17].

Several studies have evaluated the association between $\mathrm{AD}$ and respiratory allergy, in particular Kulig et al. [18] have shown that, at the age of 5 years, $50 \%$ of children with $\mathrm{AD}$ have developed allergic respiratory diseases; Ricci et al. [19] have studied 252 children with $\mathrm{AD}$, aged 6-36 months: the mean followup of these patients was $16.9 \pm 2.9$ years (range 13-22 years); in the first 10 years asthma appeared in $34.1 \%$ of cases and RC in $57.6 \%$; they concluded that the severity and good control of AD was predicable for the onset of asthma. Ohshima et al. [20] in a 4-year follow-up study of 169 children with $\mathrm{AD}$ have shown that, at the end of the study, 35\% of children developed asthma. van der Hulst et al. [21] in their systematic review have confirmed that young children with $\mathrm{AD}$ had a high risk of developing asthma in later childhood.

According to a recent study by Spergel more than 50\% of children with $\mathrm{AD}$ may develop asthma and approximately $75 \%$ allergic rhinitis during the first 6 years of life [3].

\section{Clinical Features}

In $\mathrm{AD}$, typical lesions of acute eczema can be observed in a first time, then lichenification is prevalent due to the itching. Classically AD shows different clinical features in 3 different ages: first year of life (first step), childhood (second step), and adolescence/adulthood (third step). In the first step eczematous, exudating lesions mainly affect 3/5-month-old children. Lesions are located on the scalp and on the face where the central area is typically spared. In more severe patients the extensor surfaces of limbs are also involved. Parents usually refer to physician that their babies are becoming restless and they cannot sleep at night. In the second step flexural areas of arms and legs are commonly affected. Lesions are typical of subacute or chronic eczema, drier than those of the first step. Children frequently complain a bothersome itching. In the third step patients are adolescents or adult. Furthermore in this step they present lichenified eczema usually localized in one or a few skin areas such as the face, back of neck, hands, wrists, and antecubital and popliteal fossae. Itching is usually important. Inflammatory hyper pigmentation can be observed in periocular and neck areas and the last has been described as "dirty neck". Similar lesions may be observed in other areas as on feet.

Diagnosis of $\mathrm{AD}$ is not so easy [5] because of the variety of clinical presentation, for this reason diagnostic criteria have been proposed. The first diagnostic criteria were proposed in 1977 by Hanifin and Lobitz [22]; in 1980 the diagnostic criteria by Hanifin and Rajka [5], were derived from Sulzberger's definition and from Hanifin and Lobitz's proposals. Furthermore $\mathrm{Gu}$ et al. refined these criteria in order to develop diagnostic guidelines for adults, children, and nonwhite ethnic groups suffering of $\mathrm{AD}$ [23].

In 1993, a consensus report of the European Task Force on Atopic Dermatitis [24] defined a validated scale, the SCORAD (SCORing Atopic Dermatitis), that considered the extent and severity of the eczematous lesions and the presence of two subjective symptoms: pruritus and loss of sleep. Then Oranje and coworkers [25], proposed a new SCORAD without patient's prospective, a patient-oriented SCORAD (PO-SCORAD) and the three-item severity (TIS) [26] score. The TIS score fits well with the more detailed objective SCORAD and can represent both as a prescreening system and as a useful tool for epidemiological studies. Recently in order to validate the PO-SCORAD index, a large European population study has been developed [27]. 
Hanifin et al. [28] proposed in 2001 another scoring system named EASI (Eczema Area and Severity Index), which can be applied to both $\mathrm{AD}$ children and adults. It considered four areas of the body: the head/neck, the trunk, and the upper and lower extremities. Each of the four body areas was separately assessed for erythema, induration/ papulation/edema, excoriation, and lichenification. A score ranging from 0 to 3 was used to evaluate the severity of each sign in each of the four areas. In 2004, Charman et al. [29] published a new, validated score used both for adults and children called POEM (Patient-Oriented Eczema Measure), based on patients' assessments of what constitutes disease severity. It consists of questions about the frequency of seven symptoms: itch, sleep disturbance, skin bleeding, skin weeping/oozing, skin cracking, skin flaking, and skin dryness/roughness.

IGA (Investigator Global Assessment) is another severity score tool that has been widely used in trials consisting of adults and children. IGA is a simple, 6-point scale, ranging from 0 (clear) to 5 (very severe disease), representing an overall evaluation of dermatitis that can be performed by the investigator at every consultation $[30,31]$.

A recent systematic review has identified 20 different published outcome measures, but the authors state that only EASI, SCORAD, and POEM have been adequately validated and recommend using EASI or SCORAD for an objective estimate of disease severity, plus the POEM as a measurement of eczema severity from the patient's perspective [32].

IGA is surely a good score but is not exclusive and specific to $\mathrm{AD}$. Numerous differential diagnoses of $\mathrm{AD}$ should be considered: scabies, seborrhoeic dermatitis, Langerhans cell's histiocytosis mainly in childhood, and contact dermatitis in children and adults.

\section{Therapy}

$\mathrm{AD}$ management is complex. Topical and systemic drugs are needed to control the disease. The American Academy of Dermatology has proposed detailed guidelines of care for eczema [33-35] based on the assessment of clinical severity by SCORAD or EASI indexes.

Recently, the PRACTALL (PRACTical ALLergy) consensus paper proposed a simple, step-based algorithm for eczema therapy depending on the severity [36]: (i) dry skin: it only needs hydration; (ii) mild, moderate, and severe eczema require, respectively, low-, mid-, and high-potency topical corticosteroids; furthermore topical calcineurin inhibitors TCIs can be helpful; (iii) systemic therapy is reserved to resistant eczema. This algorithm has some limitations: TCIs should not be used in children under 2 years and highpotency corticosteroids have to be avoided in children and in special sites such as the face.

The use of TCIs has been debated, in the last few years. In 2005 [37], the Pediatric Advisory Committee of the Food and Drug Administration (FDA) labeled pimecrolimus and tacrolimus as dangerous, with a black-box warning about their potential carcinogenicity. Sporadic case of cancer set during treatment are reported. However, several groups [3841] have focused on the evidence of TCIs' carcinogenetic role and have agreed that data are inconclusive and further studies must be done. Furthermore recent vehicle-controlled trials indicate efficacy of proactive treatment with tacrolimus in association with corticosteroides to prevent AE flares [42] At present however tacrolimus (Protopic) and pimecrolimus (Elidel) ointment have to be considered second-line treatments for AD in children [43].

\section{AD and Quality of Life}

$\mathrm{AD}$ is a serious problem for patients and their families, in fact, especially when severe, $\mathrm{AD}$ can be extremely disabling, causing psychological stress that, in young children, can involve the whole family. Clinicians should be aware of the psychological problems related to this disease and their impact on the child and parents' quality of life (QOL) [44].

7.1. AD and Family Life. In 1998, Lawson et al. [45] focused on QOL in the families of children affected by AD. They worked out the Dermatitis Family Impact Questionnaire, whose aim was to understand the family aspects most influenced by the disease. Their results showed that $74 \%$ of $\mathrm{AD}$ parents described a general burden of extra care, for example, relating to household cleaning and washing, preparing meals and shopping; $71 \%$ of parents described psychological pressures including feelings of guilt, exhaustion, frustration, resentment, and helplessness; night-time itching and scratching caused delay in getting the child to sleep and led to parental frustration and exhaustion in $64 \%$. So for the $66 \%$ of families a "normal" family life was not possible. Furthermore Lawson et al. [45] reported that $63 \%$ of children with $\mathrm{AD}$ had current sleep problems and most had had sleep disturbance at some time. Patients with $\mathrm{AD}$ scratch more during sleep than patients with other chronic dermatologic diseases. Pauli-Pott et al. in their study [46] stated that mothers of children with $\mathrm{AD}$ were more helpless, depressed, and overprotective than mothers of healthy children.

Ricci et al. [44] considered the parents of 45 children aged 3-84 months affected by AD were asked to complete two validated questionnaires after clinical examination (Infants' Dermatitis Quality of Life Index and Dermatitis Family Impact questionnaire). Children's QOL appeared slightly moderately altered (mean score 10.2) compared with the value of a control group (3.3), and itching, sleep problems, and the influence of the disease on the child's mood were the cause of greatest discomfort for the child. Family QOL appeared moderately altered (mean score 11) compared with the value of the control group (7.4). The greatest problem was the disturbed sleep of the family members. Other important problems were the economic cost for the management of the disease and the tiredness and irritability caused by the disease in parents. 


\section{Conclusions}

$\mathrm{AD}$ is a complex disease with needs a well standardized clinical approach. Furthermore AD often preludes to other atopic diseases. Our hope is that, in the next future, dermatologists and paediatric allergists will have standardized guidelines based on international consensus conferences. Similarly to other chronic diseases such as allergic asthma, the use of step-based therapy could be useful in the management of the disease [4]. The evaluation of the quality of life of patients and their families represents a new target, with a global consideration of problems no more limited to the skin. Although the disease mainly affects childhood, in some cases it may persist even in adulthood and may be associated with asthma and/or allergic rhinitis. The percentage of $\mathrm{AD}$ persistent cases is extremely variable, ranging from $8-13 \%$ to $60-70 \%$ [1]. On the other hand, healing data reported in the literature widely vary: some authors report $50-70 \%$ healing at the age of 10 years, others [47] $43.2 \%$ at the age of 3 , and some refer to a general improvement in $\mathrm{AD}$ severity in the first $5 / 7$ years of life [19]. The relationship between asthma and AD is complex, because different and unknown mechanisms are involved in the atopic march. Further studies about loss of function in filaggrin gene are needed to elucidate the risks related to epidermal barrier defects. Potential targets for barrier repair and prevention of atopic diseases will play a crucial role in future therapy. Much data point towards a strong correlation between AD in early infancy and the subsequent appearance of asthma. The risk of developing asthma in children with $\mathrm{AD}$ is highly variable: according to some authors, the prevalence is $25 \%$, while others suggest higher values up to $80 \%[17,19]$. In a recent study conducted by our team [1], the percentages of appearance of respiratory allergies is lower; in fact only $37.5 \%$ of children with $\mathrm{AD}$ have developed respiratory pathologies (rhinoconjunctivitis in $27 \%$ of cases and asthma alone in $17 \%$ ) after a long-term followup. In this study the high efficacy reached in preventing respiratory allergies has been attributed to the good control of $\mathrm{AD}$ in the first years of life gained through the constant and effective collaboration between dermatologists and pediatric allergologists, sometimes with the aid of a psychologist.

\section{Conflict of Interests}

The authors declare no conflict of interests.

\section{References}

[1] G. Ricci, A. Patrizi, A. Giannetti, A. Dondi, B. Bendandi, and M. Masi, "Does improvement management of atopic dermatitis influence the appearance of respiratory allergic diseases? A follow-up study," Clinical and Molecular Allergy, vol. 8, article no. 8, 2010.

[2] J. M. Spergel and A. S. Paller, "Atopic dermatitis and the atopic march," Journal of Allergy and Clinical Immunology, vol. 112, no. 6, pp. S118-S127, 2003.
[3] J. M. Spergel, "From atopic dermatitis to asthma: the atopic march," Annals of Allergy, Asthma and Immunology, vol. 105, no. 2, pp. 99-106, 2010.

[4] E. Besnier, "Premiere note et observations preliminaires pour servir d'introduction a l'etude diathesques," Annales de Dermatologie et de Syphiligraphie, vol. 4, p. 634, 1892.

[5] J. M. Hanifin and G. Rajka, "Diagnostic features of Atopic Dermatitis," Acta Dermato-Venereologica, vol. 92, supplement, pp. 44-47, 1980.

[6] S. G. O. Johansson, T. Bieber, R. Dahl et al., "Revised nomenclature for allergy for global use: report of the Nomenclature Review Committee of the World Allergy Organization, October 2003," Journal of Allergy and Clinical Immunology, vol. 113, no. 5, pp. 832-836, 2004.

[7] A. Sandilands, C. Sutherland, A. D. Irvine, and W. H. I. McLean, "Filaggrin in the frontline: role in skin barrier function and disease," Journal of Cell Science, vol. 122, no. 9, pp. 1285-1294, 2009.

[8] F. J. D. Smith, A. D. Irvine, A. Terron-Kwiatkowski et al., "Lossof-function mutations in the gene encoding filaggrin cause ichthyosis vulgaris," Nature Genetics, vol. 38, no. 3, pp. 337342, 2006.

[9] H. Baurecht, A. D. Irvine, N. Novak et al., "Toward a major risk factor for atopic eczema: meta-analysis of filaggrin polymorphism data," Journal of Allergy and Clinical Immunology, vol. 120, no. 6, pp. 1406-1412, 2007.

[10] S. Weidinger, M. O'Sullivan, T. Illig et al., "Filaggrin mutations, atopic eczema, hay fever, and asthma in children," Journal of Allergy and Clinical Immunology, vol. 121, no. 5, pp. 1203-1209.e1, 2008.

[11] C. N. A. Palmer, A. D. Irvine, A. Terron-Kwiatkowski et al., "Common loss-of-function variants of the epidermal barrier protein filaggrin are a major predisposing factor for atopic dermatitis," Nature Genetics, vol. 38, no. 4, pp. 441-446, 2006.

[12] J. Henderson, K. Northstone, S. P. Lee et al., "The burden of disease associated with filaggrin mutations: a populationbased, longitudinal birth cohort study," Journal of Allergy and Clinical Immunology, vol. 121, no. 4, pp. 872-877.e9, 2008.

[13] C. N. A. Palmer, T. Ismail, S. P. Lee et al., "Filaggrin null mutations are associated with increased asthma severity in children and young adults," Journal of Allergy and Clinical Immunology, vol. 120, no. 1, pp. 64-68, 2007.

[14] I. Marenholz, R. Nickel, F. Rüschendorf et al., "Filaggrin lossof-function mutations predispose to phenotypes involved in the atopic march," Journal of Allergy and Clinical Immunology, vol. 118, no. 4, pp. 866-871, 2006.

[15] J. Bousquet, N. Khaltaev, A. A. Cruz et al., "Allergic rhinitis and its impact on asthma (ARIA) 2008 update (in collaboration with the World Health Organization, GA(2)LEN and AllerGen)," Allergy, vol. 63, no. 86, pp. 8-160, 2008.

[16] J. D. Boot, P. Panzner, and Z. Diamant, "A critical appraisal of methods used in early clinical development of novel drugs for the treatment of asthma," Pulmonary Pharmacology and Therapeutics, vol. 20, no. 3, pp. 201-219, 2007.

[17] A. H. Liu, F. D. Martinez, and L. M. Taussig, "Natural history of allergic diseases and asthma," in Pediatric Allergy: Principles and Practice, D. Y. M. Leung, H. A. Sampson, R. S. Geha, and S. J. Szefler, Eds., pp. 10-22, Elsevier, Philadelphia, Pa, USA, 2003.

[18] M. Kulig, R. Bergmann, U. Klettke, V. Wahn, U. Tacke, and U. Wahn, "Natural course of sensitization to food and inhalant allergens during the first 6 years of life," Journal of Allergy and Clinical Immunology, vol. 103, no. 6, pp. 1173-1179, 1999. 
[19] G. Ricci, A. Patrizi, E. Baldi, G. Menna, M. Tabanelli, and M. Masi, "Long-term follow-up of atopic dermatitis: retrospective analysis of related risk factors and association with concomitant allergic diseases," Journal of the American Academy of Dermatology, vol. 55, no. 5, pp. 765-771, 2006.

[20] Y. Ohshima, A. Yamada, M. Hiraoka et al., "Early sensitization to house dust mite is a major risk factor for subsequent development of bronchial asthma in Japanese infants with atopic dermatitis: Results of a 4-year followup study," Annals of Allergy, Asthma and Immunology, vol. 89, no. 3, pp. 265-270, 2002.

[21] A. E. van der Hulst, H. Klip, and P. L. P. Brand, "Risk of developing asthma in young children with atopic eczema: a systematic review," Journal of Allergy and Clinical Immunology, vol. 120 , no. 3, pp. 565-569, 2007.

[22] J. M. Hanifin and W. C. Lobitz Jr., "Newer concepts of atopic dermatitis," Archives of Dermatology, vol. 113, no. 5, pp. 663670, 1977.

[23] H. Gu, X. S. Chen, K. Chen et al., "Evaluation of diagnostic criteria for atopic dermatitis: validity of the criteria of Williams et al. in a hospital-based setting," British Journal of Dermatology, vol. 145, no. 3, pp. 428-433, 2001.

[24] J. F. Stalder, A. Taieb, D. J. Atherton et al., "Severity scoring of atopic dermatitis: the SCORAD index. Consensus report of the European Task Force on Atopic Dermatitis," Dermatology, vol. 186, no. 1, pp. 23-31, 1993.

[25] A. P. Oranje, E. J. Glazenburg, A. Wolkerstorfer, and F. B. De Waard-Van Der Spek, "Practical issues on interpretation of scoring atopic dermatitis: the SCORAD index, objective SCORAD and the three-item severity score," British Journal of Dermatology, vol. 157, no. 4, pp. 645-648, 2007.

[26] A. P. Oranje, "Practical issues on interpretation of scoring atopic dermatitis: SCORAD index, objective SCORAD, patient-oriented SCORAD and three-item severity score," Current Problems in Dermatology, vol. 41, pp. 149-155, 2011.

[27] J.-F. Stalder, S. Barbarot, A. Wollenberg et al., "Patient oriented SCORAD (PO-SCORAD): a new self assesment scale in atopic dermatitis, validated in Europe," Allergy, vol. 66, no. 8, pp. 1114-1121, 2011.

[28] J. M. Hanifin, M. Thurston, M. Omoto, R. Cherill, S. J. Tofte, and M. Graeber, "The eczema area and severity index (EASI): assessment of reliability in atopic dermatitis," Experimental Dermatology, vol. 10, no. 1, pp. 11-18, 2001.

[29] C. R. Charman, A. J. Venn, and H. C. Williams, "The patientoriented eczema measure: development and initial validation of a new tool for measuring atopic eczema severity from the patients' perspective," Archives of Dermatology, vol. 140, no. 12, pp. 1513-1519, 2004.

[30] L. F. Eichenfield, A. W. Lucky, M. Boguniewicz et al., "Safety and efficacy of pimecrolimus (ASM 981) cream $1 \%$ in the treatment of mild and moderate atopic dermatitis in children and adolescents," Journal of the American Academy of Dermatology, vol. 46, no. 4, pp. 495-504, 2002.

[31] H. Gollnick, R. Kaufmann, D. Stough et al., "Pimecrolimus cream $1 \%$ in the long-term management of adult atopic dermatitis: prevention of flare progression. A randomized controlled trial," British Journal of Dermatology, vol. 158, no. 5, pp. 1083-1093, 2008.

[32] J. Schmitt, S. Langan, and H. C. Williams, "What are the best outcome measurements for atopic eczema? A systematic review," Journal of Allergy and Clinical Immunology, vol. 120, no. 6, pp. 1389-1398, 2007.

[33] L. F. Eichenfield, J. M. Hanifin, T. A. Luger, S. R. Stevens, and H. B. Pride, "Consensus conference on pediatric atopic dermatitis," Journal of the American Academy of Dermatology, vol. 49, no. 6, pp. 1088-1095, 2003.

[34] C. Ellis, T. Luger, D. Abeck et al., "International Consensus Conference on Atopic Dermatitis II (ICCAD II): clinical update and current treatment strategies," The British Journal of Dermatology, vol. 148, supplement 63, pp. 3-10, 2003.

[35] J. M. Hanifin, K. D. Cooper, V. C. Ho et al., "Guidelines of care for atopic dermatitis," Journal of the American Academy of Dermatology, vol. 50, no. 3, pp. 391-404, 2004.

[36] C. A. Akdis, M. Akdis, T. Bieber et al., "Diagnosis and treatment of atopic dermatitis in children and adults: European Academy of Allergology and Clinical Immunology/American Academy of Allergy, Asthma and Immunology/PRACTALL consensus report," Allergy, vol. 61, no. 8, pp. 969-987, 2006.

[37] T. Bieber, M. Cork, C. Ellis et al., "Consensus statement on the safety profile of topical calcineurin inhibitors," Dermatology, vol. 211, no. 2, pp. 77-78, 2005.

[38] L. Fonacier, E. N. Charlesworth, J. M. Spergel, and D. Y. M. Leung, "The black box warning for topical calcineurin inhibitors: looking outside the box," Annals of Allergy, Asthma and Immunology, vol. 97, no. 1, pp. 117-120, 2006.

[39] J. M. Spergel and D. Y. M. Leung, "Safety of topical calcineurin inhibitors in atopic dermatitis: evaluation of the evidence," Current Allergy and Asthma Reports, vol. 6, no. 4, pp. 270-274, 2006.

[40] A. B. Fleischer Jr., "Black box warning for topical calcineurin inhibitors and the death of common sense," Dermatology Online Journal, vol. 12, no. 6, article no. 2, 2006.

[41] G. Ricci, A. Dondi, and A. Patrizi, "Role of topical calcineurin inhibitors on atopic dermatitis of children," Current Medicinal Chemistry, vol. 14, no. 14, pp. 1579-1591, 2007.

[42] J. Schmitt, L. Von Kobyletzki, Å. Svensson, and C. Apfelbacher, "Efficacy and tolerability of proactive treatment with topical corticosteroids and calcineurin inhibitors for atopic eczema: systematic review and meta-analysis of randomized controlled trials," British Journal of Dermatology, vol. 164, no. 2, pp. 415428, 2011.

[43] R. S. Kirsner, M. P. Heffernan, and R. Antaya, "Safety and efficacy of tacrolimus ointment versus pimecrolimus cream in the treatment of patients with atopic dermatitis previously treated with corticosteroids," Acta Dermato-Venereologica, vol. 90, no. 1, pp. 58-64, 2010.

[44] G. Ricci, B. Bendandi, F. Bellini, A. Patrizi, and M. Masi, "Atopic dermatitis: quality of life of young Italian children and their families and correlation with severity score," Pediatric Allergy and Immunology, vol. 18, no. 3, pp. 245-249, 2007.

[45] V. Lawson, M. S. Lewis-Jones, A. Y. Finlay, P. Reid, and R. G. Owens, "The family impact of childhood atopic dermatitis: the Dermatitis Family Impact questionnaire," British Journal of Dermatology, vol. 138, no. 1, pp. 107-113, 1998.

[46] U. Pauli-Pott, A. Darui, and D. Beckmann, "Infants with atopic dermatitis: maternal hopelessness, child-rearing attitudes and perceived infant temperament," Psychotherapy and Psychosomatics, vol. 68, no. 1, pp. 39-45, 1999.

[47] S. Illi, E. Von Mutius, S. Lau et al., "The natural course of atopic dermatitis from birth to age 7 years and the association with asthma," Journal of Allergy and Clinical Immunology, vol. 113, no. 5, pp. 925-931, 2004. 


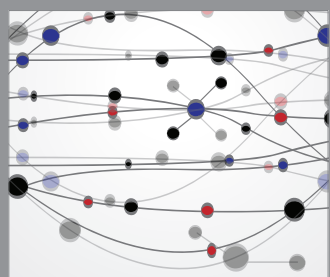

The Scientific World Journal
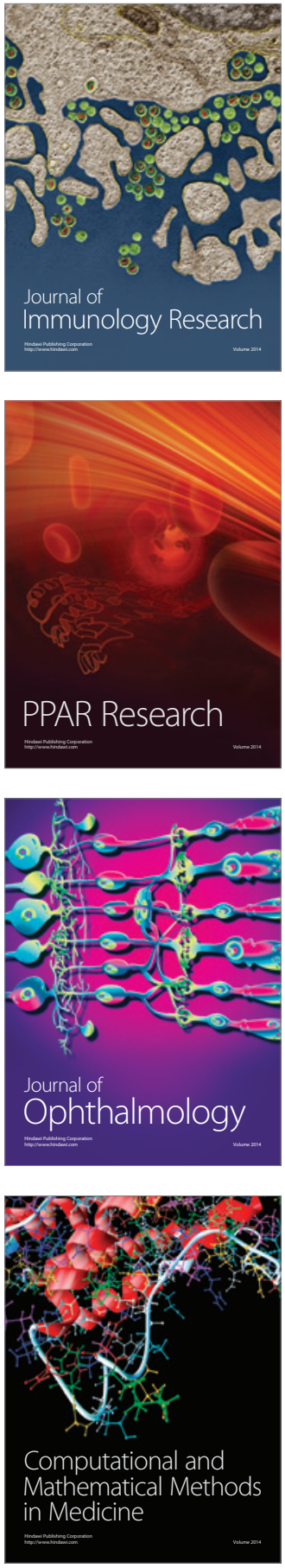

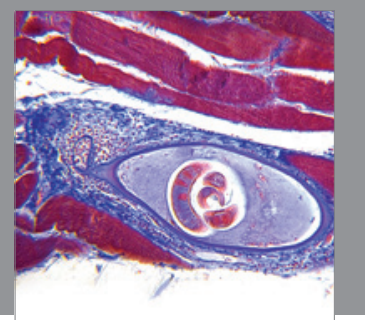

Gastroenterology

Research and Practice
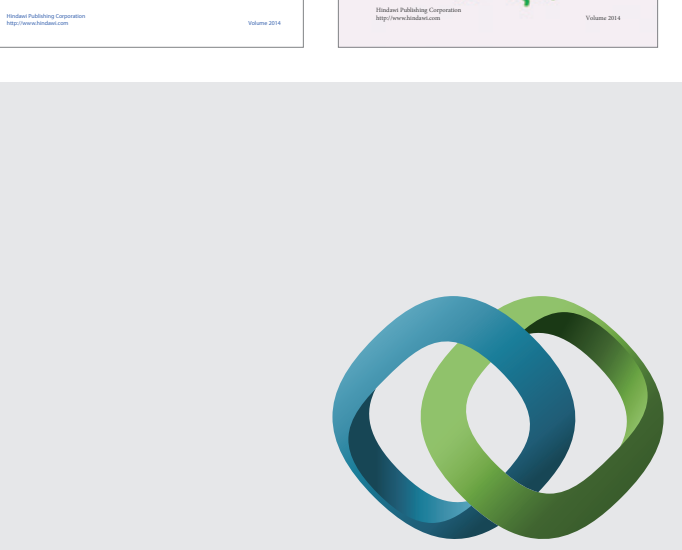

\section{Hindawi}

Submit your manuscripts at

http://www.hindawi.com
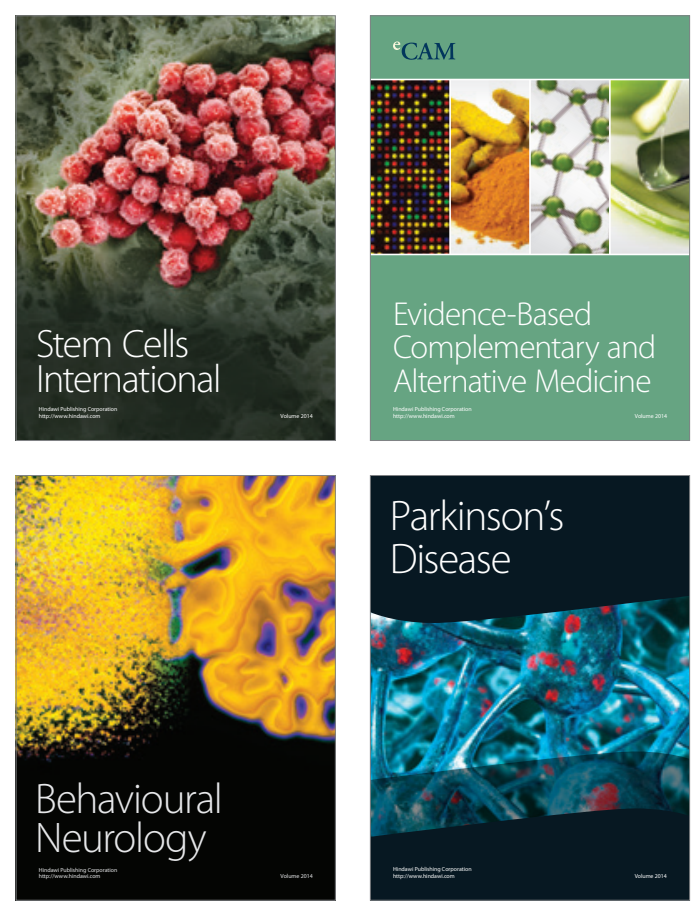

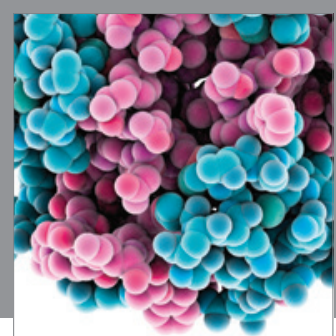

Journal of
Diabetes Research

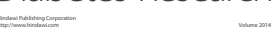

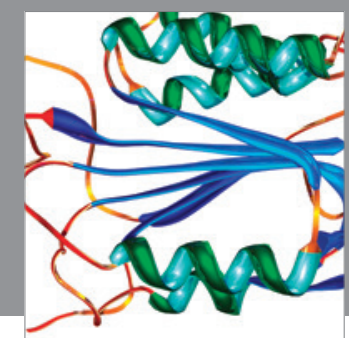

Disease Markers
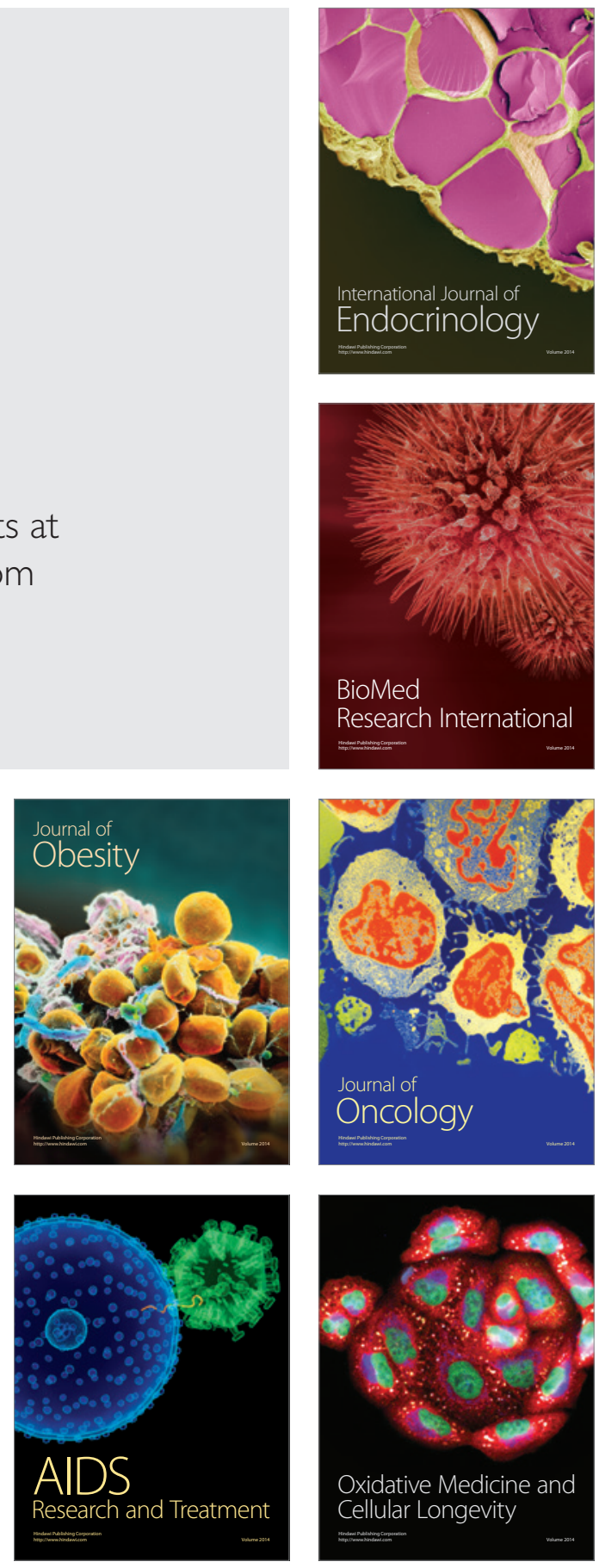